\title{
Factors influencing power consumption and power-saving measures in ESR process
}

\author{
*Yun-Long Xiong, Zhao-Wei Song, An-Guo Wang and Yan-Chun Lou \\ Shenyang Research Institute of Foundry Co., Ltd., Shenyang 110022, China
}

\begin{abstract}
Since the USA patent of electroslag remelting (ESR) metallurgy was held by P. K. Hopkins in 1940, the ESR technology has now entered a relatively mature stage after a 70-year history of development. At present, the annual capacity of ESR steels around the world is approximately 2 million tonnes. ESR metallurgy emerged in China in 1958. Since then, electroslag furnaces were gradually installed in Chinese special steel plants. At present, there are more than 200 electroslag remelting furnaces in the metallurgical workshops of these steel plants with an annual production capacity of about 500,000 tonnes of ingots and components made of about 200 varieties of steels, including high quality steels and superalloys. This ESR technology is used as a special remelting and refining method for producing high quality steels and superalloys. However, traditional ESR technology has the disadvantages of environmental pollution and extremely high specific power consumption. High power consumption restricts, to a certain degree, the competitiveness of ESR steels in the marketplace. The measures of power saving in ESR have been researched in recent years. In this paper, some factors influencing power consumption, such as filling ratio, slag system, slag amount, melting rate and furnace structure are reviewed, and several new ESR technologies for power saving are proposed.
\end{abstract}

Key words: ESR; power saving; fill ratio; slag system; slag amount; melting rate
CLC numbers: TG249.3
Document code: A
Article ID: 1672-6421(2019)01-001-07

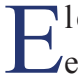
ectroslag remelting (ESR), also known as electroflux remelting, is a process of remelting and refining steels and various superalloys for mission-critical applications in areas such as aircraft, thermal power stations, nuclear power plants and military weapons or devices, and has been widely used worldwide ${ }^{[1-3]}$. This process involves two liquids: a liquid metal and a liquid slag. Each liquid is subject to a phase change due to melting and/or solidification. From a fluid dynamic point of view, the ESR process is clearly a multiphase process, with free interfaces (slag/metalpool, gas/slag), and with a mixed area (slag and falling steel droplets). The

\section{*Yun-long Xiong}

Male born in 1974, Research Fellow, Ph.D candidate. He has more than 10 years' experience in special steel casting technology research and new product development. He has participated in many national major projects, such as the National Natural Science Foundation Project, the National HighTech Research and Development (863) Program of China, and the National Science and Technology Major Project of the Ministry of Science and Technology of China. He has been authorized 5 national patents of China, and won the Second Prize of the National Technological Invention Award. To date, he has published more than 20 papers in conferences and magazines at home and abroad.

E-mail: xylxhh94@163.com

Received: 2018-09-20; Accepted: 2018-12-11 main feature of this process is the production of higher quality ingots by means of controlled solidification and chemical refining. Figure 1 shows a schematic of the ESR system. Alternating or direct current is passed from a conventionally melted and cast solid electrode through a layer of molten slag to the baseplate, which closes the electric circuit. Because of the electrical resistivity of the slag, Joule heating is generated and the slag transfers this energy to both the ingot and crystallizer (mold) surfaces and the melting electrode tip. The molten metal produced in the form of droplets or a continuous stream (depending on the melting rate) passes through the slag and builds up a solid ingot with directional solidification. The slag and the ingot are contained in a water cooled copper mold and the baseplate is also water cooled. Thus, a heat flow regime is imposed that gives controlled solidification, which produces the improved as-cast structure of ESR ingots. Another interesting feature of the ESR process is the formation of a skin of solidified slag, which provides electrical insulation to the mold and produces a smooth ingot surface ${ }^{[4-6]}$.

ESR technology has entered a relatively mature stage as an effective and advanced method of remelting and refining high quality ingot castings with its good metallurgical reaction conditions and the 


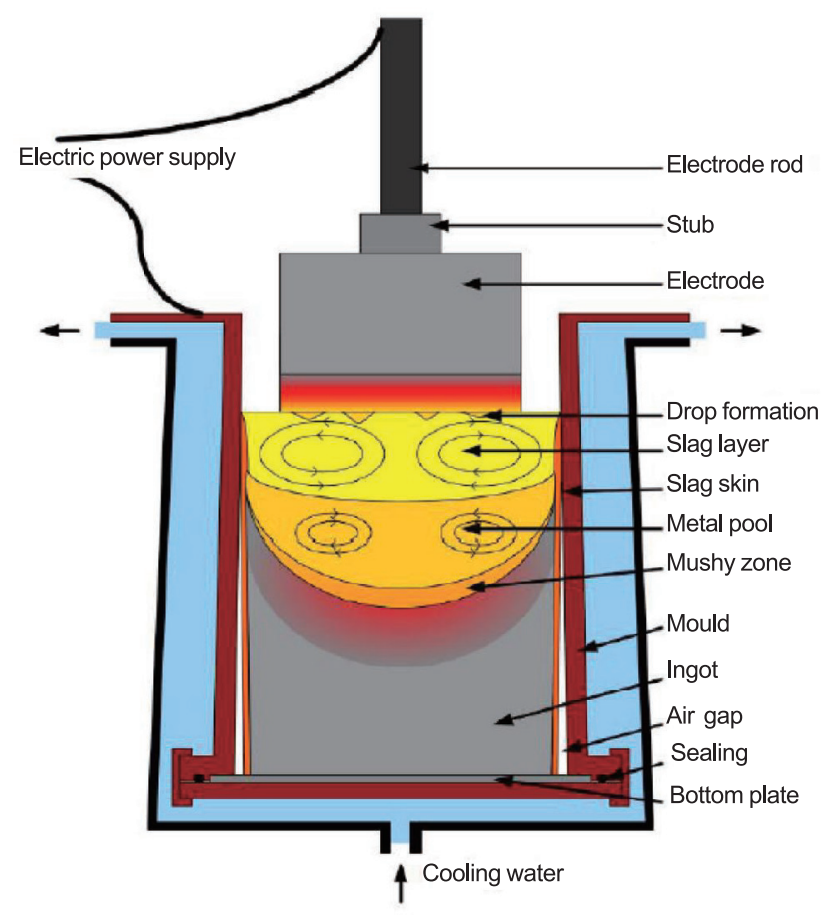

Fig. 1: Schematic diagram of electroslag remelting process

special means of crystallization process. The biggest drawback is the high power consumption ${ }^{[7]}$. According to statistics, the average power consumption of ESR steel worldwide is about 1,300 to $1,600 \mathrm{kWh}$ per tonne ${ }^{[8]}$, which is much higher than other smelting methods, such as AOD, VOD and LF, greatly increasing the cost of production. Thus, it is urgent to save power in the ESR process, which not only complies with the principle of energy conservation and emission reduction, but also has important significance in expanding the application scope of ESR technology.

Over the past several decades, the issue of high power consumption has been a concern of domestic and foreign scholars. They have made some progress through much experimental research, and some methods have been implemented in practical production, such as properly increasing the filling ratio, changing the components of the slag system with special slag, rationally arranging the loop of short net, and increasing the melting rate ${ }^{[9,10]}$. In order to provide valuable references relating to ESR for researchers, this paper reviews some factors influencing the power consumption, such as filling ratio, slag system, slag amount, melting rate and furnace structure in ESR process; and presents several new ESR technologies for power saving.

\section{Effect of filling ratio on power consumption in ESR process}

The filling ratio refers to the ratio of consumable electrode cross-sectional area to the cross-sectional area of the mold, which has a great influence on the heat distribution of the slag pool in the mold. Studies ${ }^{[11,12]}$ show that, when using a mold with a diameter of $300 \mathrm{~mm}$ to remelt $150 \mathrm{~mm}$ and 250 $\mathrm{mm}$ diameter electrodes, respectively, i.e., increasing the filling ratio from 0.25 (150 mm electrode) to $0.694(250 \mathrm{~mm}$ electrode), the melting power of the consumable electrode can be increased by $24 \%$. When high speed steel M2 was remelted using ESR with a filling ratio increased from 0.25 to 0.66 , the energy consumption could be reduced by $31 \%$. Gao Yanbin ${ }^{[13]}$ studied ways to reduce the electricity consumption of electroslag furnaces. The results indicated that when the filling ratio increases from 0.24 to 0.605 , the heat capacity absorbed by the electrode can increase about $80 \%$. Meanwhile, the heat distribution can be improved with a heat loss drop to $61.49 \%$ from $78.24 \%$; the melting power of the consumable electrode increases to $38.51 \%$ from $21.78 \%$. When US Wallace-Murray Company Simonds factory changed the filling ratio from 0.25 to 0.66 , the power consumption dropped from 1,227 to 849 $\mathrm{kWh}$ per ton, saving $378 \mathrm{kWh}$ per ton of steel ${ }^{[14]}$. Therefore, increasing the filling ratio has significant benefits for reducing power consumption, and at the same time, the use of a high filling ratio electrode can increase ingot quality and improve ingot surfaces.

One study ${ }^{[15]}$ showed that, in the process of ESR, the effect of the filling ratio on the power consumption can be achieved by changing the exothermic heat distribution in the slag pool. Figure 2 shows the exothermic heat distribution in the slag pool during the ESR process. Nos. 2, 3, 5, 6 and 7 in Fig. 2 denote the heat loss in the ESR process, among which, Nos. 3 and 5 are not easy to control. Therefore, to improve the ESR heat utilization, effective methods can be used, mainly by reducing radiant heat from slag pool to mold wall, and the rational utilization of heat from preheating and melted electrodes.

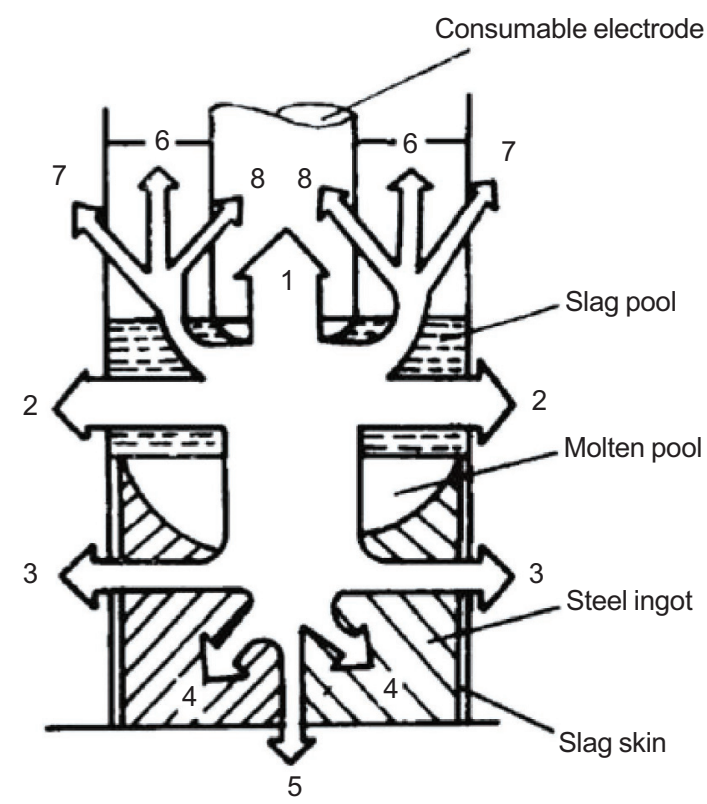

1-Heat from preheating and melted electrodes; 2-Heat from the cooling water, which is passed from slag pool to mold wall; 3 -Heat from the cooling water, which is passed from ingots to mold wall; 4-Stored heat by ingots; 5 -Heat from the cooling water inside bottom tank; 6-Radiant heat from slag pool; 7-Radiant heat from slag pool to mold wall; 8-Radiant heat from slag pool to electrode

Fig. 2: Exothermic heat distribution of slag pool in ESR process 
The whole ESR process is carried out at a high temperature. When the temperature of the slag pool is up to its maximum of $1,900{ }^{\circ} \mathrm{C}$, the slag surface temperature is about $1,700{ }^{\circ} \mathrm{C}{ }^{[15]}$. The heat loss caused by thermal radiation emitted from the slag pool surface is about $6 \%$ of the amount of heat released from the slag pool. Based on the heat conduction formula, the heat transfer of thermal radiation is primarily concerned with the area of the radiating body: the larger the area, the greater the amount of thermal radiation. When the filling ratio is increased, the heat conduction from the slag pool to the electrodes is increased due to the expansion of the heat adsorption area of the electrodes in the slag. Meanwhile, the area of thermal radiation of the slag pool exposed to air decreases, reducing the thermal radiation loss of the slag pool, thus the thermal efficiency of the ESR process is improved, and thereby the energy consumption is reduced. In the study by Jiang Xing-wei, et al. from the Northeastern University ${ }^{[16]}$, the relationship between the amount of thermal radiation from the slag pool surface $(P)$ and the mold diameter $\left(D_{\mathrm{K}}, \mathrm{mm}\right)$, and electrode diameter $\left(D_{\mathrm{E}}, \mathrm{mm}\right)$ is derived as follows:

$$
P=4.5 \times 10^{-3} \varepsilon\left(D_{\mathrm{K}}{ }^{2}-{D_{\mathrm{E}}}^{2}\right)\left(T_{\mathrm{S}} / 100\right)^{4}
$$

where $\varepsilon$ stands for the ratio of the slag/gas surface area to the slag/metal surface area; and $T_{\mathrm{S}}$ is the surface temperature of the slag pool, ${ }^{\circ} \mathrm{C}$.

Set the filling ratio as $K$, then:

$$
K=D_{\mathrm{K}}^{2} / D_{\mathrm{E}}^{2}
$$

Substituting the equation (2) into equation (1):

$$
P=4.5 \times 10^{-3} \varepsilon \cdot D_{\mathrm{K}}^{2}(1-K)\left(T_{\mathrm{S}} / 100\right)^{4}
$$

In equation (3), when the diameter of the mold, $D_{\mathrm{K}}$, is a constant, the thermal radiation of the slag pool surface, $P$, increases with a reduction in the value of $K$, which further illustrates the fact that a large filling ratio can reduce the thermal radiation loss in the ESR process, thereby reducing the power consumption as well.

In general, during the process of remelting ingots with the same specification, the length of electrode with a large filling ratio is shorter than that with a smaller filling ratio. Therefore, the voltage drop loss of electrodes with a large filling ratio is relatively smaller during the entire ESR refining cycle. ESR thermal radiation loss for a single phase ESR furnace is obvious and direct. With a large filling ratio, the doublearmed exchange ESR furnace can save time in the electrode exchange, which also serves the purpose of power saving.

\section{Effect of slag system and slag amount on power consumption in ESR process}

Molten slag works as the heating element of thermal resistance in the ESR process, so the ratio of slag components and the change in the slag amount directly affect the quality of products and energy consumption in the ESR process.

\subsection{Effect of slag system}

Studies by Shi Jian-liao, et al. ${ }^{[17-18]}$ showed that the change of components of the slag system has a great impact on the electrical resistivity. Within a certain range, the amounts of $\mathrm{CaF}_{2}$ and $\mathrm{CaO}$ are reduced, at the same time the dosage of $\mathrm{Al}_{2} \mathrm{O}_{3}$ is increased, and thus the slag conductivity is reduced, and the power consumption per tonne of steel can be reduced. Liang Lian-ke, et al. ${ }^{[19]}$ of the Northeastern University, China, adopted high calcium fluoride ANF-6 and fluoride-free calcium slag A1 as a research subject. They found that, in the temperature range of 1,500 to $1,900{ }^{\circ} \mathrm{C}$, the conductivity of molten slag ANF6 is 3 to 10 times higher than that of slag A1, and the electrical efficiency of slag A1 is $10.2 \%$ higher than that of slag ANF6. Clearly, the low electrical conductivity, low coefficient of thermal conductivity and high viscosity slag contribute much to improving power efficiency and reducing power consumption.

Paton E. R. ${ }^{[20]}$ in Ukraine thought that the electrical and thermal efficiencies in the ESR process can be expressed as follows ${ }^{[14]}$ :

$$
\begin{gathered}
\eta_{\mathrm{E}}=P_{\mathrm{em}} / P_{\mathrm{ESR}}=R_{\mathrm{S}} /\left(R_{\mathrm{S}}+R_{\mathrm{E}}\right) \\
\eta_{\mathrm{H}}=P_{\text {eff }} / P_{\mathrm{ESR}}
\end{gathered}
$$

where $\eta_{\mathrm{E}}$ is the electrical efficiency; $\eta_{\mathrm{H}}$ is the thermal efficiency; $P_{\text {ESR }}$ is the transformer output power, kVA; $P_{\text {em }}$ is the input power of slag pool, $\mathrm{kVA} ; P_{\text {eff }}$ is the power required for melting electrodes, $\mathrm{kVA} ; R_{\mathrm{S}}$ is the electrical resistance of the slag pool, $\Omega$; and $R_{\mathrm{E}}$ is the line resistance outside slag pool, $\Omega$. Therefore, the total energy efficiency of the remelting system is:

$$
\eta=\eta_{\mathrm{E}} \cdot \eta_{\mathrm{H}}
$$

From the equation above, it can be known that improving the electrical efficiency and the thermal efficiency of the slag pool are conducive to improving the overall energy efficiency of the system, thereby the melting power consumption can be reduced. It is known from Equation (4) that increasing the electrical resistance of the slag pool, $R_{\mathrm{S}}$, and reducing the line resistance, $R_{\mathrm{E}}$, can both improve the electrical efficiency.

When a strong current runs through the slag pool, the slag pool can be seen as a resistance element. It meets the first law of thermodynamics and Ohm's law, according to the basic resistance formula:

$$
R_{\mathrm{S}}=\rho \cdot L / A
$$

where $\rho$ stands for electrical resistivity of molten slag, $\Omega \cdot \mathrm{m} ; L$ for distance from the electrode melting end to the metal pool, $\mathrm{mm}$; and $A$ for area of consumable electrode buried in the slag pool, $\mathrm{m}^{2}$.

Therefore, the effect of the slag system on the power consumption ultimately comes down to the electrical conductivity of the slag system. The electrical conductivity of various components in the slag system differs from each other, and changes in the components of the slag system can 
greatly affect the power consumption in the remelting process. When other conditions remain unchanged, using a high resistance slag system in the remelting process leads the power consumption to be reduced. Especially, when a high electrical resistance slag with low content of fluoride is combined with the use of a "high filling ratio" electrode, the energy saving can be more significant.

\subsection{Effect of slag amount}

The effect of slag amount on the power consumption in the ESR process is mainly reflected in: (1) the depth of the slag pool (especially the distance from the electrode tip to the metal bath surface) and the slag resistance have a positive correlation; (2) the depth of the slag pool and the heat carried away by the mold cooling water have a negative correlation.

Li Zheng-bang, et al. concluded in their research ${ }^{[21]}$ that a shallower slag pool can reduce the power consumption in the ESR process. Liu Zhong-jing and Cui Yao-wu's research ${ }^{[22}$ showed that lower energy consumption can be achieved by a reduction in the amount of slag, an increase in the filling ratio and/or the use of a high resistance quaternary slag system, and the combined use of these measures has obvious effect on energy-saving. An optimum range of slag amount must be met besides the consideration of purification effect, because beyond a certain limit, the result will be the contrary. It is true that the reduction of slag amount can reduce the heat carried away by the cooling water, but too small a slag amount makes the electrodes buried in the slag pool too shallow and this causes a high slag surface temperature, which results in an increase in the thermal radiation loss. When reduction of the heat loss by cooling water is not greater than the increase of the thermal radiation loss, the power consumption will increase.

Previous research by Mao Hong-xiang, et al ${ }^{[23]}$ showed that the theoretical slag amount in the ESR process should be consistent with the Equation (8) of maximum resistance, which is also embodied in Equation (7), for the slag amount is decided by the area of consumable electrode buried in the slag pool $(A)$ and the distance from electrode melting end to metal pool $L$ :

$$
R_{\mathrm{S}}=\sqrt{r^{2}+X_{\mathrm{L}}^{2}}
$$

where $R_{\mathrm{S}}$ stands for slag resistance; $r$ is the line resistance; $X_{\mathrm{L}}$ is the line inductance.

In addition, the slag amount can be determined by the following three calculation methods ${ }^{[7]}$ :

(1) Calculated by the weight of steel ingot:

$$
G_{\text {slag }}=(4 \%-5 \%) G_{\text {ingot }}
$$

where $G_{\text {slag }}$ is weight of slag, and $G_{\text {ingot }}$ is weight of steel ingot.

(2) Use the slag utilization factor $\left(K_{\text {slag }}\right)$, generally $K_{\text {slag }}$ is between $22-25$, that is, $1 \mathrm{~kg}$ slag can melt 22 to $25 \mathrm{~kg}$ ingots:

$$
G_{\text {slag }}=G_{\text {ingot }} / K_{\text {slag }}
$$

(3) Empirical formula, especially for remelting some products with a variable cross-section, the key is to determine the thickness/depth of the slag layer:

$$
G_{\text {slag }}=\frac{\pi}{4} D_{\text {mold }}^{3} \cdot f_{\text {slagdepth }} \cdot r_{\text {slag }}
$$

where $D_{\text {mold }}$ is the diameter of mold; $f_{\text {slagdepth }}$ (the factor of slag depth) is the ratio of slag depth to the diameter of mold, which is about $0.5 ; \gamma_{\text {slag }}$ is the slag density. For conventional slag $\left(70 \% \mathrm{CaF}_{2}+30 \% \mathrm{Al}_{2} \mathrm{O}_{3}\right), \gamma_{\text {slag }}$ is $0.0025 \mathrm{~kg} \cdot \mathrm{cm}^{-3}$.

Production practice in Shenyang Research Institute of Foundry Co., Ltd. shows Equations (9) and (10) are suitable for special shaped castings' ESR process, and Equation (11) is suitable for cylindrical castings' ESR process.

Therefore, in the ESR process, selecting an appropriate slag pool depth is very important to reduce the power consumption to some degree.

\section{Effect of electroslag furnace structure on power consumption in ESR process}

Studies by Li Zheng-bang et al. ${ }^{[21,24-25]}$, showed that the following methods can be used to improve the efficiency of the furnace and reduce power consumption. Such methods include shortening the central distance between the transformer and the furnace, reducing the length of the short net, or improving the secondary structure of the network by electromagnetic inductance of the short net, reducing the secondary inductance of the short net or decreasing the loss of voltage drop of the short net ${ }^{[23]}$. For instance, compared with the eletroslag furnace with unipolar power, the eletroslag furnace employing a bipolar series to supply power can reduce power consumption and also shorten the time of exchanging electrodes, which is beneficial for increasing productivity and improving products quality ${ }^{[26-28]}$.

In addition, the following methods can be adopted to reconstruct the existing supporting pillar of eletroslag furnaces: enhancing the magnetic isolation effect to reduce magnetic induction losses; using an electrode holder with low level contact resistance to minimize the contacts of the short net system; strengthening the isolation between the bottom tank and mold; or, reducing or even avoiding the circuit shunt of electrode, slag surface, mold wall and bottom tank. All of these can serve the purpose of reducing the power consumption of $\operatorname{ESR}^{[2,30]}$.

\section{Effect of melting rate on power consumption in ESR process}

Melting rate is an important parameter in the ESR process. Not only can rational selection of the melting rate ensure the solidified ingot quality, but can also reduce the power consumption to the smallest possible amount or degree ${ }^{[21]}$.

If the other conditions are not changed, simply increasing the melting rate will reduce the overall melting time, resulting 
in a power saving. In the study by Fei Wu-yuan and Jiang Zhou-hua ${ }^{[31]}$, the melting rate was increased from $3 \mathrm{~kg} \cdot \mathrm{min}^{-1}$ to $6.6 \mathrm{~kg} \cdot \mathrm{min}^{-1}$, then the power consumption was reduced from 1427 to $904 \mathrm{KWh} \cdot \mathrm{t}^{-1}$, giving a net saving of $523 \mathrm{kWh}$ per ton steel. Yu Qiang et al. ${ }^{[32]}$ and Deng Xin et al. ${ }^{[33]}$ at Northeastern University, China, developed a melting rate intelligent control system for the electroslag furnace, and put it into actual production. This system has the functions of continuously changing load-tap and accurately controlling the depth of the electrode inserting into the slag pool, which can make the melting rate continuously adjustable within the range of 5 to $20 \mathrm{~kg} \cdot \mathrm{min}^{-1}$. After application to more than 20 industrial electroslag furnaces, it was shown that this system has advantages of high reliability, good stability in running, friendly user interface and easy operation and maintenance. Especially, it can better guarantee the quality of ingots, reduce electric energy consumption and increase the productivity. Shi Jian-liao and Zhang Ya-li ${ }^{[17]}$ conducted a research on the power consumption per ton of steel under various melting rates, and then established a simple linear model:

$$
q_{\mathrm{pc}}=q_{\max }-1.64\left(V_{\text {actual }}-V_{\max }\right)+k
$$

where $q_{\mathrm{pc}}$ stands for the power consumption per ton of steel, $\mathrm{kWh} \cdot \mathrm{t}^{-1} ; q_{\max }$ for the maximum power consumption per ton of steel, $\mathrm{kWh} \cdot \mathrm{t}^{-1} ; V_{\text {actual }}$ for the actual melting rate, $\mathrm{kg} \cdot \mathrm{min}^{-1} ; V_{\max }$ for the melting rate at maximum power consumption per ton of steel, $\mathrm{kg} \cdot \mathrm{min}^{-1}$; and $k$ for the correction factor which varies with the other factors generally. It can be seen from the above model that the higher the melting rate, the lower the power consumption.

To change the electrode melting rate, the most commonly used method is to control the basic melting parameters of current, voltage, and slag pool depth in the ESR process. In recent years, some scholars at home and abroad have developed a number of new technical methods to change the electrode melting rate in the ESR process. Bai Hai-jun et al. ${ }^{[34-35]}$ applied electromagnetic stirring technology to the ESR process to eliminate the defects in ESR ingots such as macro segregation and shrinkage cavity. In electromagnetic stirring technology, the heat transfer is reinforced in liquid and the obtained flat-shaped molten metal pool increases the electrode melting rate to some degree. Chumanov I. V. and Chumanov V. I. ${ }^{[36]}$ used the rotating electrode method to improve production efficiency in the ESR process by over $25 \%$, which cut power consumption and also improved the solidification quality of the ingot. Wang Fang and Chen Rui, et al. ${ }^{[37-40]}$ adopted a vibrating electrode remelting method to increase the electrode melting rate, which cut the power consumption by over $10 \%$ compared with the traditional method of ESR.

In short, an appropriate increase in the melting rate can shorten the overall melting time, thus reducing heat loss. This will significantly increase the effective power and reduce power consumption. However, if the melting rate is too high, the molten metal pool will be deeper, and thus worsen the quality of the solidified ingot.

\section{Effect of second-generation electroslag metallurgy technologies on power consumption}

With the development of modern electroslag metallurgy technology, the second generation of electroslag metallurgy technologies, such as liquid metal electroslag pouring technology, electroslag rapid remelting technology (ESRR) and electroslag continuous casting technology are being widely used. Study on the second generation of electroslag metallurgy technology by Ding Jia-wei, et al. ${ }^{[41-44]}$ showed that the power consumption of the second generation liquid metal electroslag pouring technology is very low because of no electrode preparation and low heat loss; it is about 400 to $500 \mathrm{kWh} \cdot \mathrm{t}^{-1}$, only $1 / 3$ to $1 / 4$ of the first generation. The heavier the ingot, the more evident the advantage. Inteco Company, Austria, developed an electroslag rapid remelting technology (ESRR) on the basis of conductive mold and double-loop principle ${ }^{[45]}$. Their research showed that when the diameter of the remelted ingot is less than $300 \mathrm{~mm}$, the melting rate in electroslag continuous casting was 1 to 3 times faster than that in traditional ESR. They found a power consumption drop of $20 \%$ to $30 \%$, and the ingot quality remained almost the same as that in the traditional ESR. To improve production efficiency and save power consumption, Zang Xi-min ${ }^{[46,47]}$ developed an innovative technology-electroslag continuous casting technology. This is a combination of electroslag remelting technology and continuous casting technology.

It can be concluded that the second-generation electroslag metallurgy technology plays a role in power saving, but further study is required for these technologies to be expanded for application.

\section{Summary}

In the present paper, various methods for power saving in the ESR process were discussed. Summary as follows can be concluded:

(1) The voltage drop loss of electrodes with a large filling ratio is relatively small. With a large filling ratio, the doublearmed exchange ESR furnace can shorten the time of exchange electrodes, so it is profitable to save power.

(2) Using a high resistance slag system in the ERS process can reduce power consumption. When a high electrical resistance slag with low fluoride is combined with the use of a "high filling ratio" electrode, an energy saving effect is evident. Also, it is very helpful and useful for power saving to select an appropriate slag pool depth.

(3) Enhancing the magnetic isolation effect can reduce the magnetic induction loss; using the electrode holder with a low level contact resistance will minimize the contacts of the short net system; strengthening the isolation effect between the bottom water tank and mold can reduce or even avoid the circuit shunt of electrode, slag surface, mold wall and bottom 
water tank.

(4) The appropriate increase of melting rate can shorten the overall melting time, consequently reducing power consumption.

(5) Application of second-generation electroslag metallurgy technology can decrease significantly power consumption because of no electrode preparation and low heat loss, and the heavier the ingot, the more evident the advantage.

However, due to the complexity and characteristics of the ESR process, every power saving method has its own limitations, which need to be further studied.

With the development of modern industry, it is believed that the following technologies will be the focus of future research on power saving in the ESR process:

(1) The charged crystallizer can keep the slag bath and metal pool temperature constant during the exchange of electrodes, where the fluid flow velocity is much faster and temperature field of the slag bath is more uniform. Therefore, the solidification quality and surface quality of hollow ingots should be greatly improved.

(2) The electrode vibration method has a relatively better power saving effect, thereby it is a very promising new method of ESR process. But, its industrial application should be a future research hot spot.

(3) Low-frequency power supply electroslag furnace can reduce the inductive reactance of loss, and improve power efficiency. Therefore, it should be considered in the future design of electroslag furnaces.

\section{References}

[1] Li Zhengbang. Principle and application of electroslag metallurgy. Beijing: Metallurgical Industry Press, 1996: 104-120. (In Chinese)

[2] Choudhary M, Szekely J, Medovar B I, et al. Velocity field in the molten slag region of ESR systems: a comparison of measurements in a model system with theoretical predictions. Metallurgical Transactions B, 1982, 13(1): 35-43.

[3] Hernandez-Morales B and Mitchell A. Review of mathematical models of fluid flow, heat transfer, and mass transfer in electro slag remelting process. Iron making and Steelmaking, 1999, 26(6): 423-438.

[4] Kajikawa K, Ganesh S, Kimura K, et al. Forging for advanced trubine applications: Development of multiple alloy rotor forging for turbine application. Ironmak \& Steelmak, 2007, 34(3): 216220.

[5] Choudhary M and Szekely J. The effect of temperature dependent electrical conductivity on flow and temperature fields in slags in ESR systems. Metall. Mater. Trans. B, 1981, 12(2): 418-421.

[6] Wang Qiang, He Zhu, Li Baokuan, et al. A General Coupled Mathematical Model of Electromagnetic Phenomena: TwoPhase Flow, and Heat Transfer in Electroslag Remelting Process Including Conducting in the Mold. Metallurgical and Materials Transactions B, 2014, 45(6): 2425-2441.

[7] Medovar B I, Medovar L B, Saenko V Yu. Electroslag technologies in the 21st century. Advanced in Special Electrometallurgy, 2001, 17(1): 14-19.

[8] Li Zhengbang. New Progress of 21st century metallurgical slag. Special Steel, 2004, 25 (5): 1-5. (In Chinese)
[9] Dong Yanwu, Jiang Zhouhua, Li Zhengbang. Electroslag Metallurgy Technology with Potential for Development. China Metallurgy, 2009, 19(4): 1-7. (In Chinese)

[10] Fu Jie. The second generation of electroslag metallurgy technology and major equipment manufacturing. China Metallurgy, 2010, 20(5): 1-4. (In Chinese)

[11] Iron and steel institute, steel metallurgical department room. Iron and Steel Research Institute. Beijing: Metallurgical Industry Press, 1975: 75. (In Chinese)

[12] Principles and Practice of Electroslag Remelting, Translated by Lu Xicai, et al., Northeastern University Press, 1990: 130. (In Chinese)

[13] Gao Yanbin. Introduction to the main means to reduce power consumption of electroslag furnace. Industrial Heating, 1994, 18 (2): 47-49. (In Chinese)

[14] Luchk J, Roberts R J. In: Proceedings of the 4th International Symposium on Electroslag Remelting Processes, Tokyo, 1973: 149

[15] Li Zhengbang. Principles and Practice of Electroslag Remelting Beijing, Metallurgical Industry Press, 2010: 43. (In Chinese)

[16] Jiang Xingwei, et al. Electroslag Remelting Process Parameters for Matching Calculation and Heat Balance Equation. ESR Collections, Shenyang: Northeastern University Press. (In Chinese)

[17] Shi LiaoJian, Zhang Yali. Ways of Reducing Power Consumption in Bipolar Series ESR. Wide and Heavy Plate, 2011, 17(6): 20 22. (In Chinese)

[18] Lin YenMin, et al. Studies on the Effect of $\mathrm{H} 13$ Steel Electroslag Process on Power Consumption. Southern metal, 2006, 148(1): 25-27. (In Chinese)

[19] Liang Lianke, Yang Huai, Guo Zhongwen. The effect of slag physical properties on power consumption of ESR process. Northeast Institute of Technology, 1993, 83(14): 171-175. (In Chinese)

[20] Barton, Elmet-Roll. Electroslag furnace. Translated by Li Zhengbang, Beijing: National Defense Industry Press, 1983.

[21] Li Zhengbang, Jiang Jinwen, et al. Ways of Reducing the Power Consumption of ESR. New Technologies, 1982, (3): 2-4. (In Chinese)

[22] Liu Zhongjing, Cui Yaowu. Analysis of the Practice of Reducing Power Consumption in Electroslag Remelting Furnace. Sichuan Metallurgy, 1984, (3): 35-40. (In Chinese)

[23] Mao Hongxiang. Researches on Saving Power in ESR Metallurgy Energy, 1983, 2 (6): 16-20. (In Chinese)

[24] Zhang Xiangfa, Zhao Yunhai. Useful Methods for Anshan Iron and Steel Group Corp. to Reduce the Power Consumption in Electroslag Furnace. Anshan Iron and Steel Technology, 1979 (4): 35-37. (In Chinese)

[25] Cao Hongmin. Analysis and Calculation of ESR Furnace Power Consumption. Industrial Heating, 1994, (3): 20-23. (In Chinese)

[26] Li Zhengbang. Electroslag metallurgy equipment and technology. Beijing: Metallurgical Industry Press, 2012: 163. (In Chinese)

[27] Chang Lizhong, Shi Xiaofang, et al. Effect of Low-Frequency AC Power Supply During Electroslag Remelting on Qualities of Alloy Steel. Journal of Iron and Steel Research, International, 2009, 16 (4): 7-11.

[28] Dong Yanwu, Jiang Zhouhua, et al. A Novel Single Power Two Circuits Electroslag Remelting with Current Carrying Mould. ISIJ International, 2016, 56(8): 1386-1393.

[29] EGTPD Ing, DFAD Ing. Process for saving energy in electroslag remelting with the use of cheaper raw material and at the same time improved ingot quality. German Patent: DE3632551, 1988. 04.07 .

[30] GTEPD Ing. Process for saving energy in the electroslag remelting process and in the alloying of metals. German Patent: DE3440820, 1986.05.15. 
[31] Wu Yuanfei, Jiang Zhouhua. Determine the Melting Rate of the Electrode Remelting Process. Journal of Materials and Metallurgy, 2002(2): 115-119. (In Chinese)

[32] Yu Qiang, Sun Guohui, et al. The Development and Application of Electroslag Furnace Intelligent Control System. Chinese Metallurgy, 2006, 16(12): 20-23. (In Chinese)

[33] Deng Xin, Jiang Zhouhua, et al. The Development and Application of Electroslag Furnace Melting Rate Control. Northeastern University (Natural Science Edition), 2011, 32(1): 94-97. (In Chinese)

[34] Bai Haijun, Li Ying, Li Baokuan. The Effect of Electromagnetic Stirring on the Steel Ingot of Temperature Field in ESR. Special Steel, 2008, 29(1): 7-9. (In Chinese)

[35] Wang Fang, Li Baokuan. Electromagnetic Field in ESR Process and Joule Thermal Analysis. Metal Technology, 2010, 46(7): 794-799. (In Chinese)

[36] IV Chumanov, VI Chumanov. Technology for Electroslag Remelting with Rotation of the Consumable Electrode. Metallurgist, 2001, 45: 125-128.

[37] Wang Fang, Lou Yanchun, Chen Rui, et al. Effect of vibrating electrode on temperature profiles, fluid flow, and pool shape in ESR system based on a comprehensive coupled model. China Foundry, 2015, 12(4): 285-292.

[38] Wang Fang, Wang Qiang and Li Baokuan. Comparison of Thermo-electromagneto-hydrodynamic Metaphysical Fields in ESR Furnace with Vibrating and Traditional Electrodes. ISIJ International, 2017, (57)1: 91-99.

[39] Wang Fang, Wang Qiang, Lou Yanchun, et al. Investigation of heat transfer and magneto hydrodynamic flow in electroslag remelting furnace using vibrating electrode. JOM, 2016, 68(1): 410-420.
[40] Chen Rui, Song Zhaowei, Xiong Yunlong, et al. The basic Research on ESR Process Under the Effect of Vibrating Electrode. In: Proc. China Foundry Week, Suzhou, 2012: 667671. (In Chinese)

[41] Ding Jiawei, Ding Gang, Qiang Yinghuai. Researches on secondary electroslag metallurgy process. Materials and Metallurgy, 2011 (10): 147-153. (In Chinese)

[42] Dong Yanwu, Jiang Zhouhua, Cao Haibo, et al. Study of SinglePower, Two-Circuit ESR Process with Current-Carrying Mold: Development of the Technique and Its Physical Simulation. Metallurgical \& Materials Transactions B, 2016, 6 (47): 1-7.

[43] Dong Yanwu, Jiang Zhouhua, et al. Simulation of Multi-electrode ESR Process for Manufacturing Large Ingot. ISIJ International, 2012, 52(12): 2226-2234.

[44] Fu Jie. Development of first and seondary generation electroslag metallurgical technology. Special Steel, 2010, 31(1): 18-23. (In Chinese)

[45] Zang Ximin, Jiang Zhouhua. Electroslag Continuous Casting of Billets of Alloyed Steels with Bifilar Mode. Proceedings of the 2007 International Symposium on Liquid Metal Processing and Casting, 2007: 101. (In Chinese)

[46] Zang Ximin. Development and Technology Research on Electroslag Continuous Casting. Shenyang: Northeastern University, 2008. (In Chinese)

[47] Zang Ximin, Jiang Zhouhua. Electroslag continuous casting of billets of alloyed steels with bifilar mode. Metallurgical Research \& Technology, 2008, 105(2): 80-83. 